\title{
BMJ Open Non-pharmacological interventions to achieve blood pressure control in African patients: a systematic review
}

\author{
Monique Cernota, ${ }^{1}$ Eric Sven Kroeber (D) , ${ }^{1}$ Tamiru Demeke, ${ }^{2}$ Thomas Frese, ${ }^{1}$ \\ Sefonias Getachew, ${ }^{2}$ Eva Johanna Kantelhardt (1D , ${ }^{3}$ Etienne Ngeh Ngeh, ${ }^{4,5,6}$ \\ Susanne Unverzagt (i) ${ }^{1,7}$
}

To cite: Cernota M, Kroeber ES, Demeke T, et al. Nonpharmacological interventions to achieve blood pressure control in African patients: a systematic review. BMJ Open 2022;12:e048079. doi:10.1136/ bmjopen-2020-048079

- Prepublication history and additional supplemental material for this paper are available online. To view these files, please visit the journal online (http://dx.doi.org/10.1136/ bmjopen-2020-048079).

Received 04 January 2021 Accepted 26 January 2022

Check for updates

(C) Author(s) (or their employer(s)) 2022. Re-use permitted under CC BY-NC. No commercial re-use. See rights and permissions. Published by BMJ.

For numbered affiliations see end of article.

Correspondence to

Dr Eric Sven Kroeber; eric.kroeber@posteo.de

\section{ABSTRACT}

Objectives This systematic review aims to evaluate the evidence of non-pharmacological strategies to improve blood pressure (BP) control in patients with hypertension from African countries.

Design We performed a systematic review and searched Medline, Central, CINAHL and study registers until June 2020 for randomised studies on interventions to decrease BP of patients with hypertension in African countries.

We assessed the study quality using the Cochrane risk of bias tool and narratively synthesised studies on nonpharmacological hypertension interventions.

Setting We included studies conducted in African countries.

Participants Adult African patients with a hypertension diagnosis.

Interventions Studies on non-pharmacological interventions aiming to improve BP control and treatment adherence.

Outcomes Main outcomes were BP and treatment adherence.

Results We identified 5564 references, included 23 with altogether 18153 participants from six African countries. The studies investigated educational strategies to improve adherence ( 11 studies) and treatment by healthcare professionals (5 studies), individualised treatment strategies (2 studies), strategies on lifestyle including physical activity (4 studies) and modified nutrition (1 study). Nearly all studies on educational strategies stated improved adherence, but only three studies showed a clinically relevant improvement of BP control. All studies on individualised strategies and lifestyle changes resulted in clinically relevant effects on BP. Due to the type of interventions studied, risk of bias in domain blinding of staff/participants was frequent (83\%). Though incomplete outcome data in $61 \%$ of the studies are critical, the general study quality was reasonable.

Conclusions The identified studies offer diverse low-cost interventions including educative and taskshifting strategies, individualised treatment and lifestyle modifications to improve BP control. Especially trialled physical activity interventions show clinically relevant BP changes. All strategies were trialled in African countries and may be used for recommendations in evidence-based guidelines on hypertension in African settings.

PROSPERO registration number CRD42018075062.

\section{Strengths and limitations of this study}

- This systematic review summarises evidence on a wide range of different non-pharmacological interventions, adding a comprehensive overview to the literature that can support physicians and healthcare policymakers in the African setting.

- Most of the included studies were conducted in urban areas of few Western and Southern African countries leading to a lack of generalisability to other African regions and showing a need of future research in rural areas.

- A main limitation of this systematic review occurs through deviations from the protocol. Due to the amount of search results for the initially planned more general scope on cardiovascular diseases, we decided to focus on hypertension.

- Nevertheless, this review was limited to studies with the highest level of evidence to investigate the benefits and harms of non-pharmacological interventions on blood pressure control in African patients with hypertension.

- This review adds to the scope of a recently published systematic review on the efficacy of common pharmacological treatment for patients with hypertension in sub-Saharan Africa.

\section{BACKGROUND}

Hypertension is a major public health problem and affects the lives of about 1.13 billion people. ${ }^{1}$ The highest blood pressure (BP) levels shifted from high to low-income countries in South Asia and sub-Saharan Africa $(\mathrm{SSA})^{2}$ with a prevalence of $57 \%$ in older adults in African countries. ${ }^{34}$ The estimated number of adults with raised BP in SSA rose from 30 million in 1975 to over 100 million in 2016 due to population growth, ageing and westernisation of lifestyle. ${ }^{2}$ Hypertension is a leading risk factor of cardiovascular disease (CVD), chronic kidney disease and diabetes. ${ }^{1}$ Studies show that black people suffer from more severe forms of hypertension associated with more frequent treatment failure 
and more severe and earlier target organ damage, all resulting in higher morbidity and mortality. ${ }^{5}$ Hypertension is a major contributor to devastating health events like stroke or heart failure, ${ }^{7-9}$ which can be catastrophic to both individuals and healthcare systems in which resources are scarce.

Tackling and reducing the burden of premature mortality due to non-communicable diseases (NCDs) through prevention and treatment has been a designated goal within the United Nations (UN) 2030 Agenda. ${ }^{10}$ The Pan-African Society of Cardiology developed an algorithm including recommendations on screening, diagnosis and treatment to achieve 25\% hypertension control in Africa by 2025 with a treatment target value of less than 140/90 mm Hg. Screening programmes are proposed to be carried out in healthcare facilities as well as public places like markets and churches. The treatment starts with lifestyle modifications, is intensified through a monotherapy and a subsequent combination of two or three medications in higher stages and resistant forms of hypertension. In some cases, the assessment of secondary causes by specialists is recommended. ${ }^{9}$

However, the awareness of hypertension remains relatively low in many parts of Africa, hindering adequate screening, treatment and control to lower the long-term risks. ${ }^{11-13}$ Extensive counselling and education of patients and healthcare providers on the importance of adherence to medications and lifestyle modifications is necessary in order to improve hypertension control. ${ }^{14}{ }^{15}$ Especially patients with multiple medications benefit from the support of their healthcare providers to understand the treatment's purpose. ${ }^{16}$

Evidence is needed detailing regional differences in hypertension incidences, risk factors, and, as subject of this review, treatment strategies in different, transitioning populations on the African continent. Seeley et al recently published a systematic review on the efficacy of common pharmacological treatment for patients with hypertension in SSA. ${ }^{17}$ These interventions do not include treatment strategies like lifestyle modifications (eg, nutritional modifications, physical activity) or educational strategies, which can be summarised as non-pharmacological interventions. ${ }^{18}$ The main aim of this systematic review is to summarise the best available evidence on the effectiveness of non-pharmacological strategies on BP control in African patients with hypertension.

\section{METHODS}

A protocol of this systematic review was prospectively registered on PROSPERO (CRD42018075062) following the Preferred Reporting Items for Systematic Reviews and Meta-Analyses (PRISMA) guideline ${ }^{19}$. We initially planned to include randomised controlled trials (RCTs) on all CVDs. Due to the high number and heterogeneity of eligible studies, we decided to focus this review on patients with hypertension as one of the main risk factors for other CVDs. We aim to describe all non-pharmacological
Table 1 Inclusion and exclusion criteria

Design RCTs conducted in African countries, in international studies with at least $50 \%$ African countries

$\begin{array}{ll}\text { Population } & \begin{array}{l}\text { African adult patients in secondary and } \\ \text { tertiary prevention, diagnosis and treatment of } \\ \text { hypertension } \\ \text { Exclusion of patients with gestational diabetes, } \\ \text { pre-eclampsia or eclampsia }\end{array} \\ \text { Intervention } & \begin{array}{l}\text { All non-pharmacological strategies to improve } \\ \text { adequate diagnoses, prevention and treatment } \\ \text { of hypertension }\end{array} \\ \text { Control } & \text { No intervention } \\ & \text { Standard care } \\ \text { Outcome } & \text { Blood pressure (SBP, DBP, MAP) and } \\ & \begin{array}{l}\text { adherence to recommendations (medications } \\ \text { and lifestyle changes) within longest follow-up }\end{array} \\ \text { Publication } & \begin{array}{l}\text { Full-text publications according to CONSORT } \\ \text { in English or German }\end{array}\end{array}$

CONSORT, Consolidated Standards of Reporting Trials; DBP, diastolic blood pressure; MAP, mean arterial pressure; RCTs, randomised controlled trials; SBP, systolic blood pressure.

hypertension interventions in detail in order to broaden the scope of the existing evidence.

\section{Patient and public involvement}

The conception of this systematic review was discussed in detail with members and students at the Addis Ababa School of Public Health in order to consider the priorities in the African context. Consensus was to gather evidence on hypertension treatment as a measure of tackling the burden of NCDs which is part of the UN 2030 Agenda. ${ }^{10}$ No patients were involved.

\section{Inclusion and exclusion criteria}

We included full-text publications on $\mathrm{RCTs}^{20}$ including cross-over RCTs and cluster RCTs on non-pharmacological interventions with adult patients with hypertension in African countries and reported results on BP. The study aims were improvement of prevention, diagnoses and treatment of hypertension in African countries. Studies on primary prevention were excluded due to the high variety of possible participants and interventions. International multicentre studies were included if more than $50 \%$ of centres were set in African countries. For detailed inclusion criteria, see table 1 .

\section{Literature search and study selection}

Two electronic databases (Medline Ovid, Central) and registers of ongoing and completed studies (International Clinical Trials Registry Platform) were searched to identify all relevant studies (see online supplemental file 1). We added a search in CINAHL to cover nursing interventions. The main keywords of the search strategy included hypertension, high blood pressure, blood 
pressure control, Africa, a list of all African countries and randomized controlled trials. The first searches in 2017 included all CVDs, while updated strategies were limited to hypertension. The last search was conducted in June 2020. All searches were done without time frame constrictions. The study selection process was described in a flow chart according to the PRISMA statement. ${ }^{19}$ We exported articles retrieved from the literature search into a reference manager software $\left(\right.$ EndNote $\left.^{21}\right)$. Duplicate references were identified in case of congruence of authors, title, year, and journal and deleted.

Titles, abstracts and full texts of potentially eligible articles were independently screened by three authors (MC, ESK and SU). Disagreements were resolved through consensus.

\section{Interventions}

This systematic review compares non-pharmacological interventions to improve adequate diagnoses, prevention and treatment of patients with hypertension with standard care, no intervention or another, less intensive or frequent intervention (table 1). Non-pharmacological interventions are considered non-medication treatment strategies such as educational programmes for patients or health professionals, individualised treatment, physical activity or nutrition-modification strategies. ${ }^{18}$

\section{Outcomes}

The main goal of non-pharmacological interventions for patients with hypertension is to improve BP control through the implementation of recommended lifestyle changes, attendance to follow-up visits and interventions promoting adherence to take hypertensive medications. We therefore report results on BP and adherence (table 1).

\section{Data extraction and management}

One author (MC or SU) extracted and a second author (SU or ESK) checked all information on study design and setting, participants, interventions and main results by using an assessment form in Excel. The form was especially designed for this systematic review and piloted for the first five studies.

We extracted information on the publication (study name consisting of the name of first author and year of the first publication of final results, registration and additional publications), study characteristics (design, country and region in which the study was conducted, duration, preplanned outcomes), participants (with inclusion/ exclusion criteria, randomised sample size, prevention level, grade of hypertension, mean age, baseline BP), a short description of the intervention and control groups, and the main results on BP and adherence within the longest follow-up periods. The grade of hypertension was described as mild (grade 1, 140-159/90-99 mm Hg), moderate (grade 2, 160-179/100-109 mm Hg) or severe (grade $3, \geq 180 / \geq 110 \mathrm{~mm} \mathrm{Hg}) \cdot{ }^{15}$ If $\mathrm{BP}$ was reported in standing and supine position, we extracted results for supine position.

All effect sizes were reported with their corresponding CIs. They were calculated either on the basis of mean and SD for metric outcomes or by comparing the frequencies of better adherence or BP control. Positive mean differences (MDs) describe a positive treatment effect on BP with lower mean values or higher decrease in the intervention group. Relative risks (RRs), HRs and ORs compare the frequency of good adherence or BP control. Effect measures greater than 1 describe a better adherence or BP control in the intervention group.

\section{Quality assessment and risk of bias}

Risk of bias was evaluated for all studies based on the Cochrane risk of bias tool. ${ }^{22}$ Two investigators (MC or ESK and SU) independently assessed the risk of bias in seven domains (sequence generation, allocation concealment, blinding of personal and participants, blinding of outcome assessors, incomplete outcome data, selective outcome reporting and other sources of bias). Risk of bias due to selective outcome reporting was judged as low, when the study protocol was available and results on all preplanned outcomes were reported. Incomplete outcome data were judged as high, when more than $10 \%$ of randomised participants dropped out. Other sources of bias were reported to be high in cases of missing sample size calculation, no definition of the primary endpoint or no reporting of baseline values.

\section{Data synthesis}

The main aim of this review is a narrative synthesis of studies with their participants, different types of interventions and resulting outcomes. We added a figure visualising the effect sizes on BP of different types of interventions in forest plots using RevMan. ${ }^{23}$ Due to the high clinical heterogeneity between included studies with their different settings, interventions, control groups and lengths of follow-up, we did not pool any results.

Treatment effects were described as statistically significant or clinically relevant. Statistically significant results on $\mathrm{BP}$ with $\mathrm{MD}$ over $5 \mathrm{~mm} \mathrm{Hg}$ were defined as clinically relevant.

\section{RESULTS}

We identified a total of 5564 references from electronic databases and 18 references from the International Clinical Trials Registry Platform. Three hundred forty articles were potentially eligible and full texts were assessed for the inclusion and exclusion criteria. Of those, 298 articles were excluded including 13 articles on studies to treat heart failure, 7 articles on coronary heart diseases and 76 articles on pharmacotherapy for hypertension (see list of excluded studies in the online supplemental material 1). Twenty-three studies (reported in 42 articles) ${ }^{24-66}$ on non-pharmacological strategies to treat patients with hypertension matched the inclusion criteria and were 


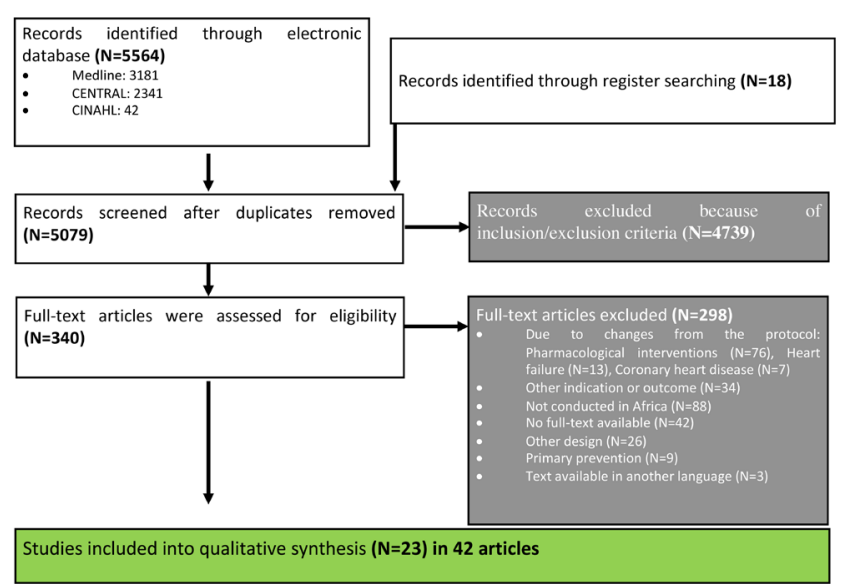

Figure 1 Preferred Reporting Items for Systematic Reviews and Meta-Analyses flow chart describing the process of study selection.

included in this systematic review (figure 1 and list of included studies in the online supplemental material 2). The characteristics and main results of these studies were summarised in table 2 .

\section{Study characteristics}

We identified 15 studies with two or more independent parallel groups and individual randomisation of patients and eight cluster RCTs with randomisation of different observation units, such as independent villages, healthcare facilities or different geographical regions (table 2). Most of the included studies were conducted in Nigeria (11 studies) and South Africa (8 studies), others in Ghana, Kenya, Cameroon and Egypt. One of the studies ${ }^{25}$ recruited patients in three countries (South Africa, Nigeria and Kenya). Nine studies (39\%) were at least partly conducted in rurally located healthcare facilities (figure 2). ${ }^{24} 2732$ 34-36 525664 The included studies were published between 1991 and 2019. Only three of the studies, all conducted in South Africa, were published before 2010. ${ }^{316061}$

\section{Participants}

The total sample size ranged from 30 to 4722 participants with a total number of 18153 participants (table 2). Eighteen studies $(78 \%)$ randomised more than 100 participants. The mean age was between 45 and 63 years. Most studies $(\mathrm{n}=19)$ included more women. Two studies to enhance physical activity included women (Khalid $e t a l)^{63}$ or men (Lamina) ${ }^{37}$ only. Mean systolic BP (SBP) at baseline was between 128 and $175 \mathrm{~mm} \mathrm{Hg}$, mean diastolic BP (DBP) between 76 and $117 \mathrm{~mm} \mathrm{Hg}$. Most studies included patients in secondary prevention with mild to moderate hypertension. Three studies ${ }^{56566}$ included patients with hypertension post-stroke.

\section{Intervention}

Studies investigated educational strategies to improve adherence of patients and treatment by healthcare professionals (16 studies), to individualise treatment (2 studies), and to change lifestyle via enhanced physical activity (4 studies) or modified nutrition (1 study) (table 2).

\section{Educational strategies to improve adherence}

Sixteen studies (17090 participants), with follow-up periods from 2 weeks in a short-term feasibility study (Wahab et $a l)^{66}$ up to 18 months (Goudge $e t a l$ ), ${ }^{34}$ were published between 1991 and 2019.

The main aim of 11 studies was the improvement of patients' knowledge on hypertension and adherence to self-monitoring of $\mathrm{BP}$, recommendations on medication, lifestyle changes and regular attendance at healthcare facilities. ${ }^{2427-29} 36565860616466$ Five studies investigated strategies to improve adequate treatment of patients with hypertension by clinicians, nurses and healthcare workers. ${ }^{32} 34355262$

Eight studies 2728365658606164 investigated the efficacy of adherence promotion via counselling and phone or letter-based interventions. Seven studies ${ }^{24} 293234355266$ investigated the efficacy of interventions on the basis of training measures with subsequent task-shifting to nurses or health workers for home visits and patient education. One study (Steyn et $a l)^{62}$ tested a multifaced intervention to implement national South African guidelines into primary care of patients with hypertension or diabetes. Another two studies investigated the efficacy of financial incentives as an additional health insurance coverage $(\text { Gyamfi et } a l)^{35}$ or free treatment (Labhardt et al), ${ }^{36}$ respectively.

Nearly all studies stated improved medication adherence, ${ }^{24} 2829366061$ implementation of lifestyle recommendations (Ayodapo and Olukokun, Mendis et al), ${ }^{27} 52$ linkage to care, ${ }^{365264}$ or knowledge and practical skills of healthcare professionals (Fairall et al, Gyamfi et al). ${ }^{32} 35$ In only three studies, ${ }^{27-29}$ these improvements resulted in modest benefits on BP (table 2 and figure $3 \mathrm{~A}-\mathrm{C}$ ). In the study by Ayodapo and Olukokun, ${ }^{27}$ counselling had a positive impact on lifestyle behaviour and resulted in a clinically relevant decrease of mean arterial BP $(-9.8 \mathrm{~mm} \mathrm{Hg}$; $95 \%$ CI -11.5 to -8.1 ). Bobrow et $a l^{28}$ assessed the effect of automated treatment adherence support delivered via mobile phone short messages. Bolarinwa et $a l^{29}$ trialled home-based follow-up care with education and counselling of patients and modifications of environmental characteristics. Both studies achieved a 12\% higher BP control with $\mathrm{SBP}<140 \mathrm{~mm} \mathrm{Hg}$ and $\mathrm{DBP}<90 \mathrm{~mm} \mathrm{Hg}$ in participants of the intervention compared with the control groups (RR: $1.12 ; 95 \%$ CI 1.01 to 1.23 and $1.12 ; 95 \%$ CI 1.00 to 1.25 ) (figure 3 ).

\section{Individualised treatment strategies}

Two studies (286 participants) with follow-up periods of 3 and 12 months were published in 2011 and 2017 (Akintunde et al, Okeahialam et al).$^{25} 55$ Both investigated strategies on the efficacy of an individualised therapy. Therapy individualisation based on the patients' renin/ 


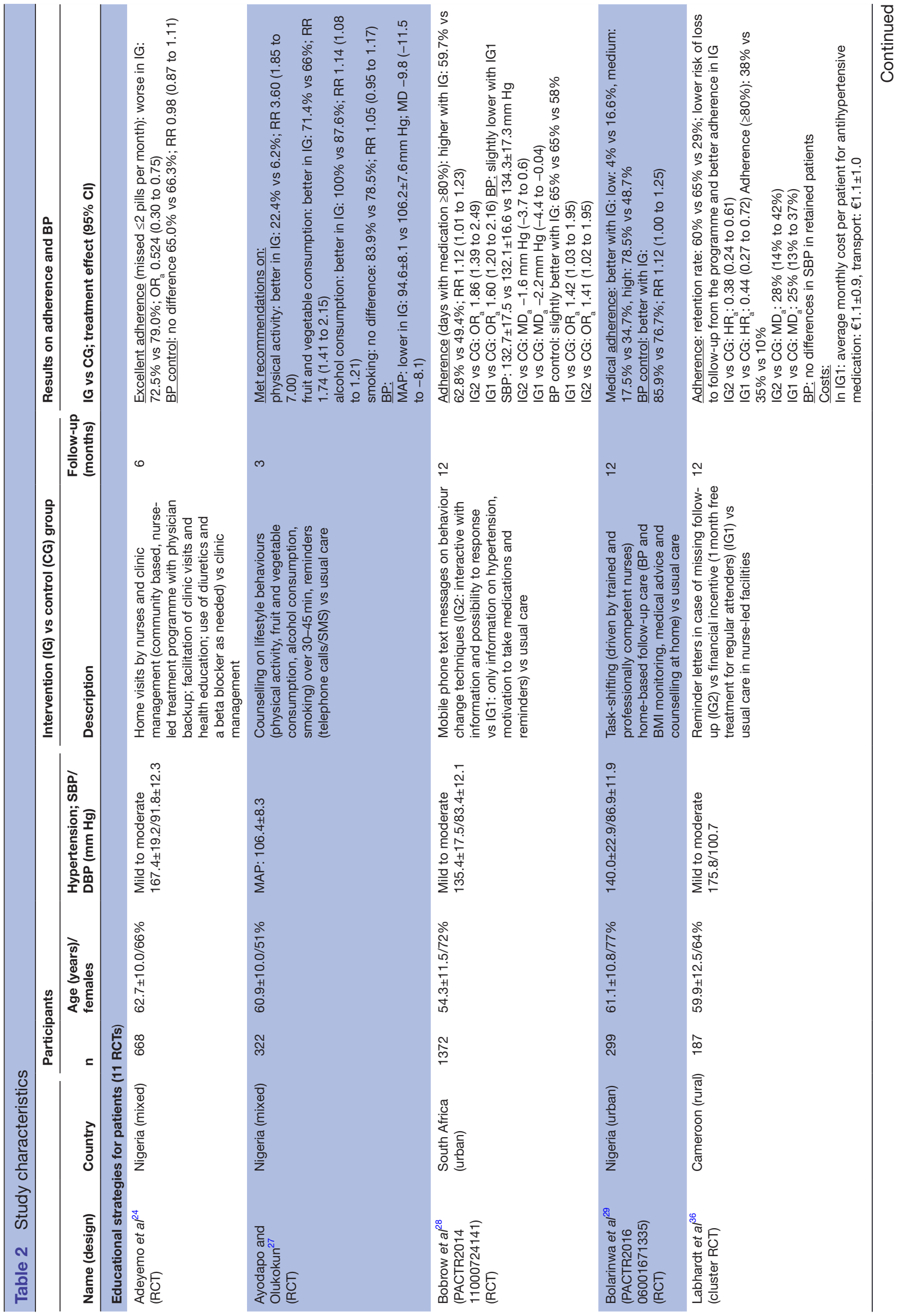




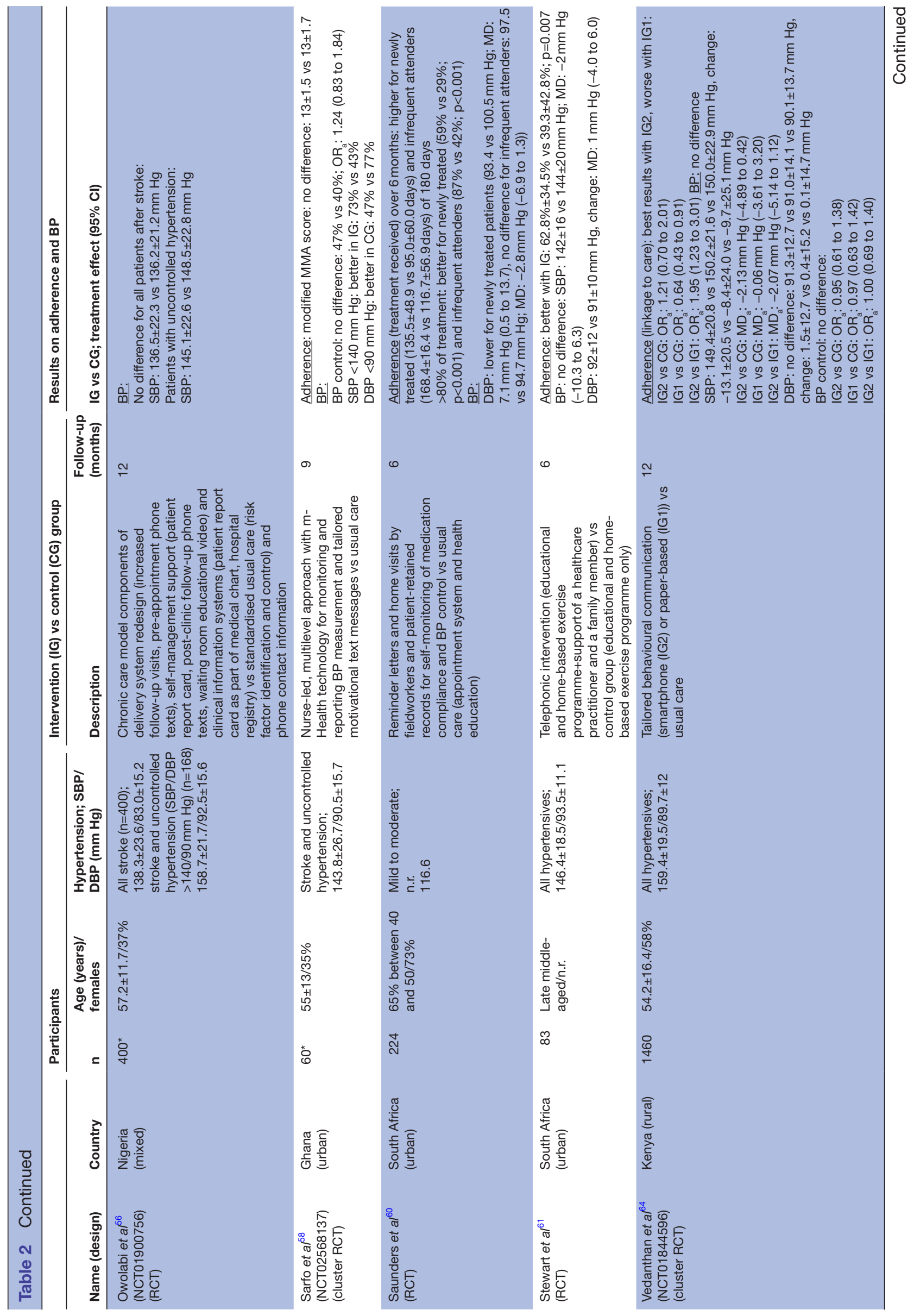




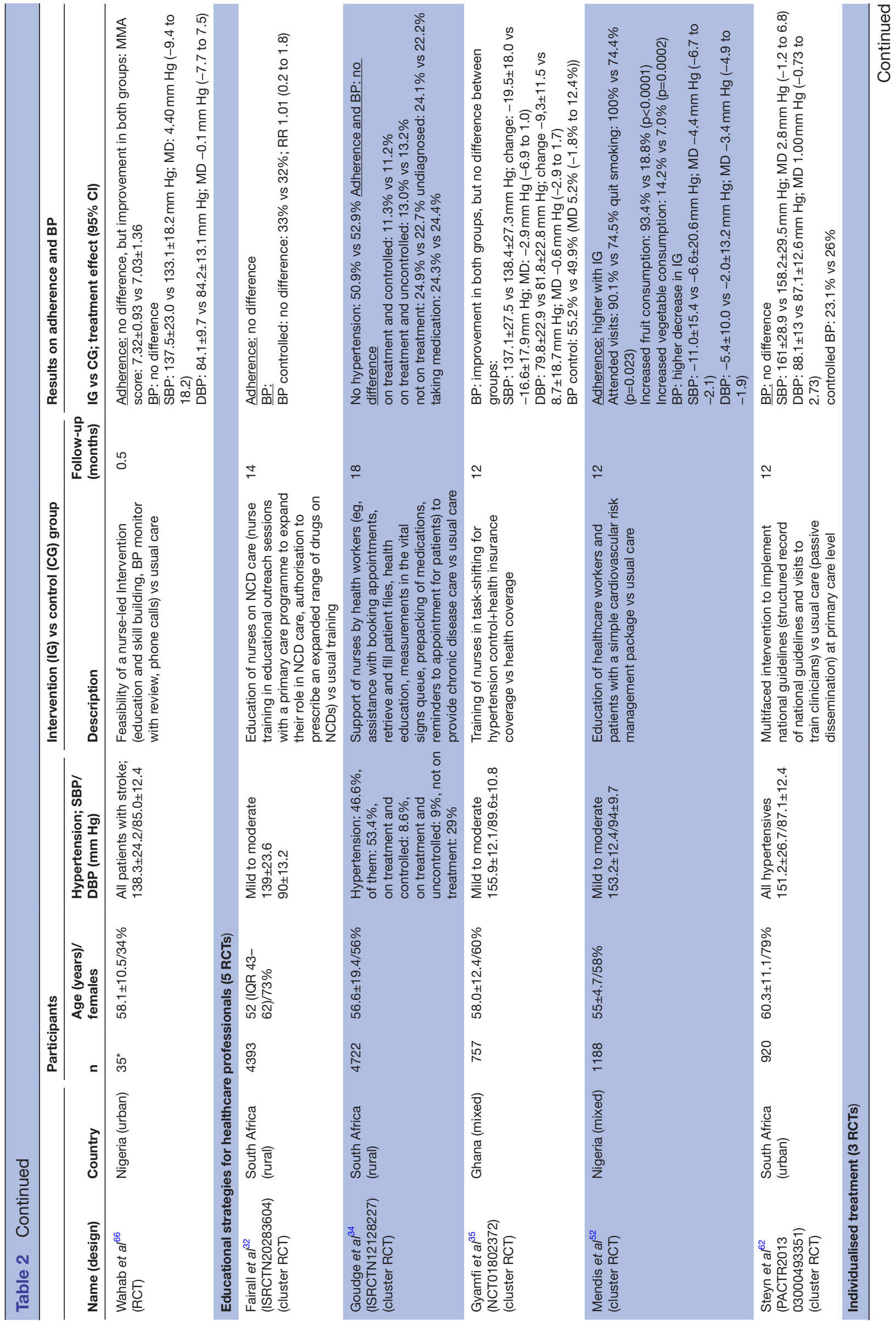




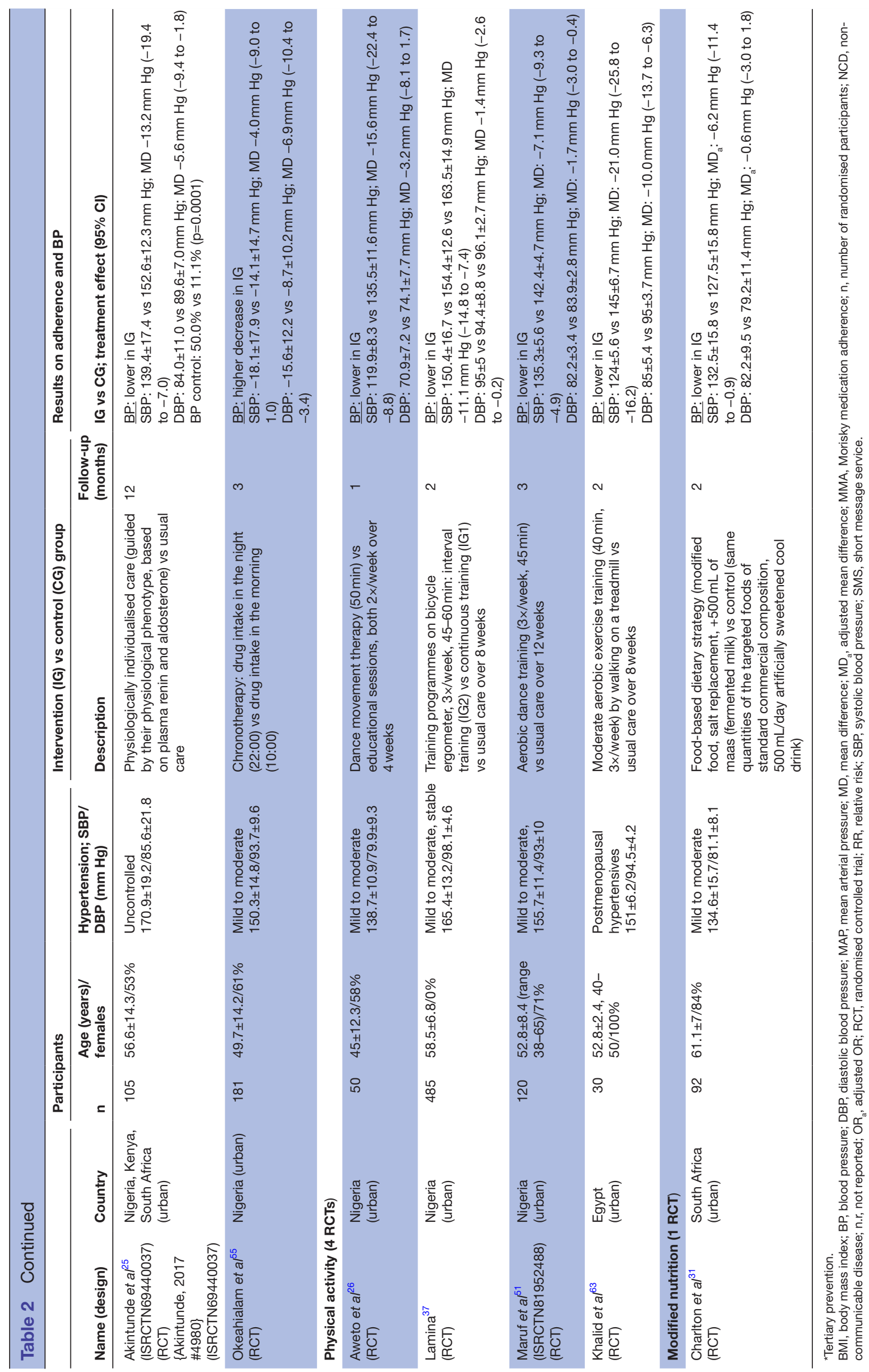




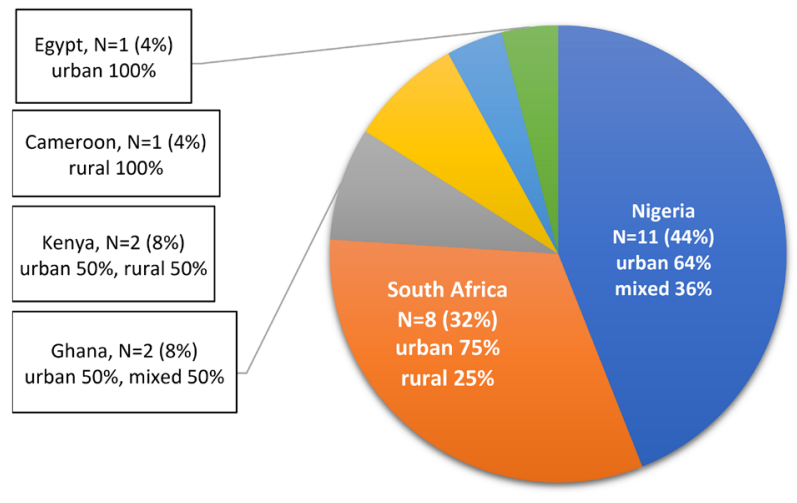

Figure 2 Spatial distribution of countries in which randomised studies were conducted.

aldosterone profile (Akintunde $e t a l)^{25}$ resulted in more appropriate prescriptions and a relevant decrease of SBP (MD: $-13.2 \mathrm{~mm} \mathrm{Hg}$; 95\% CI -19.4 to -7.0 ) and DBP (MD: $-5.6 ; 95 \%$ CI -9.4 to -1.8 ) in patients with uncontrolled hypertension. The second study (Okeahialam et $a l)^{55}$ showed a higher reduction of DBP in patients using their anti-hypertensives at night compared with a morning intake (MD: $-6.9 \mathrm{~mm} \mathrm{Hg}$; 95\% CI -10.4 to -3.4 ) but stated no change in SBP (table 2).

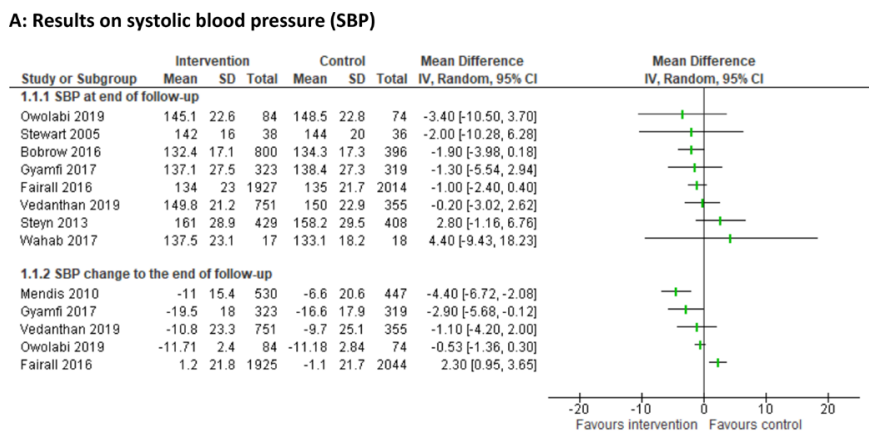

B: Results on diastolic blood pressure (DBP)

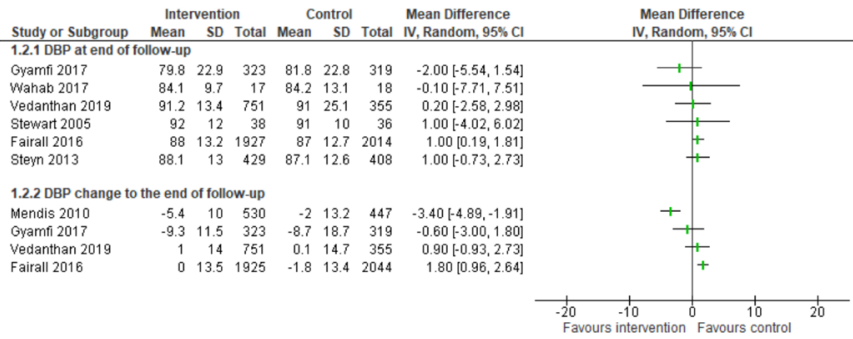

C: Results on Blood pressure (BP) control

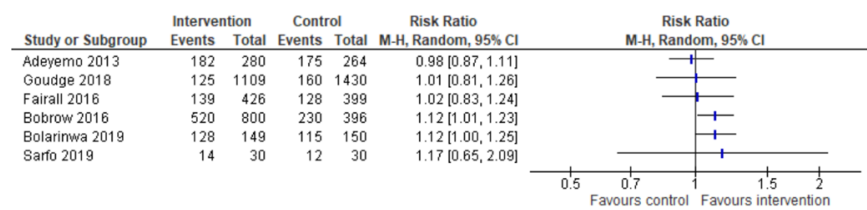

Figure 3 Results of educational strategies to improve adherence (3a Results on systolic blood pressure; 3b Results on diastolic blood pressure; $3 c$ Results on blood pressure control)
A: Results on systolic blood pressure (SBP)

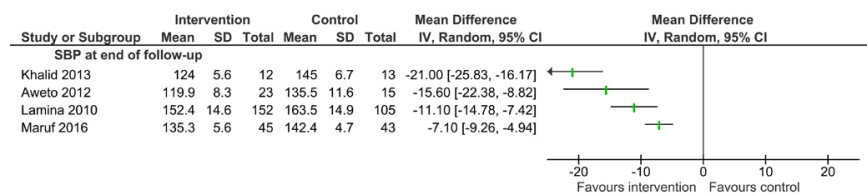

B: Results on diastolic blood pressure (DBP)

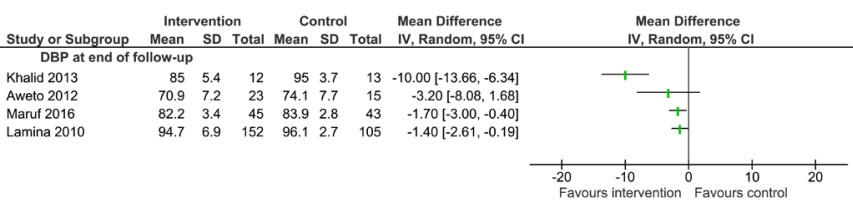

Figure 4 Results of strategies to enhance physical activity (4a Results on systolic blood pressure; 4b Results on diastolic blood pressure).

Strategies with physical activity

Four studies ${ }^{26375163}$ (685 participants), published between 2010 and 2016, investigated the BP-lowering effect of different aerobic training strategies over 4-12 weeks. Enhanced physical activities were performed two or three times a week and included dance training (Aweto et al, Maruf $e t a l)^{2651}$ and exercise training on an ergometer (Lamina) ${ }^{37}$ or treadmill (Khalid et al) ${ }^{63}$

All studies stated a clinically relevant benefit with mean reductions of SBP between 21 and $7.1 \mathrm{~mm} \mathrm{Hg}$ and DBP between 10 and $1.4 \mathrm{~mm} \mathrm{Hg}$ (figure 4). The highest BP decrease was achieved in a study on the effect of moderate aerobic exercise training by walking on a treadmill in postmenopausal women with hypertension (Khalid et $a l)^{63}$ (MD: -21 mm Hg; 95\% CI -25.8 to -16.2).

Modified nutrition strategies

Charlton et $a l^{31}$ tested a food-based dietary strategy (reduced salt consumption) in 92 patients with mild to moderate hypertension from a low socioeconomic background, stating a clinically relevant decrease in SBP after 2 months (MD: $-6.2 \mathrm{~mm} \mathrm{Hg}$; 95\% CI -11.4 to -0.9 ), but no effect on DBP (table 2 ).

\section{Potential biases}

The greatest restriction of study quality was a high risk of bias in the blinding of staff and study participants in 19 studies. Especially educational strategies were not examined in double-blinded studies, however three of these studies ${ }^{34} 5658$ reported a quality assurance against detection bias with blinded measurement of BP. Two studies on physical activity enhancement in comparison with usual care (Lamina, Maruf et $a)^{3751}$ were described as double blinded without reporting further details. Only the study on modified nutrition (Charlton et $a l)^{31}$ adequately reported detailed methods to ensure blinding of participants and fieldworkers. Another frequent problem was incomplete outcome data in 14 studies with loss to follow-up of over $10 \%$ of randomised participants or per-protocol analyses. Selective reporting was checked in all 13 studies with a published protocol. Of those, five studies $^{29} 35365156$ did not report all preplanned outcomes. 
Problems concerning randomisation were identified in three studies with a non-random component in sequence generation or allocation concealment. ${ }^{25352}$ Other sources of bias include missing sample size calculations, reporting of intermediate results only and relevant differences at baseline in nine studies (table 3, figure 5). ${ }^{24-26295155636466}$

\section{DISCUSSION}

This systematic review describes interventions and treatment effects of 23 studies with a total of 18153 participants with hypertension from six African countries. Most of the studies investigated successful low-cost concepts to improve BP control through improved adherence to medical treatment and lifestyle changes.

While lower-income and middle-income countries' CVD mortality remained unchanged over the last decades, high-income countries have reduced the CVD mortality by more than $50 \%$ since $1990,{ }^{67}$ largely by using countryspecific guidelines, evidence-based policy interventions to reduce risk factor levels, strengthening the health system at the primary care level and improving acute care with attention to early initiation of treatment. However, policies to reduce population-wide risk factors of hypertension have not been widely adopted in low-income and middle-income countries. ${ }^{68}$

Pharmacotherapy with the well-established antihypertensive medications is the mainstay of hypertension management. ${ }^{15} 69$ Nevertheless, treatment recommendations on adherence to medication and changed lifestyle habits are often only incompletely applied in practice. ${ }^{70-72}$ Patients are frequently unwilling to take drugs due to possible side effects. They may benefit from adequate knowledge as well as a higher motivation to take their prescribed medications and to implement sustainable lifestyle changes. ${ }^{73-75}$ Despite the frequent lack of acute symptoms, uncontrolled BP may result in severe longterm outcome and increased mortality. The risk increases in cases of inadequate treatment and low patient adherence as well as inconsistent follow-up on BP control. ${ }^{7}$ Therefore, all strategies with the aim to increase knowledge, awareness and adherence are essential to lowering BP levels and improving the prognoses of patients. ${ }^{69} 76$ Due to the short-term follow-up, no study reported longterm outcomes on mortality, and we interpreted available results on BP changes and treatment adherence.

Several strategies to improve health-related behaviour concerning hypertension with convincing results were examined. We identified eight studies that investigated the efficacy of phone or letter-based interventions (eg, via short message service) to improve knowledge on hypertension, with adherence support or reminder letters for follow-up. ${ }^{2728} 365658606164$ All these studies showed strong effects of the intervention concerning self-reported behavioural changes, but only two of these studies showed improved BP during follow-up (Ayodapo and Olukokun, Bobrow et al)..$^{27} 28$ Three studies ${ }^{29} 3552$ reported improved adherence and two of those a decreased BP level through nurse-led interventions (Bolarinwa et al, Mendis et al). ${ }^{29} 52$ These studies demonstrated the efficacy of task-shifting interventions in a low-resource setting. Furthermore, lowcost interventions suited to the environment, including financial incentives for adherent patients with minimal additional resources, can significantly improve the adherence of patients (Labhardt et $a l)^{36}$ and thus potentially influence BP control.

Even though cost-effective interventions are globally available, there are major gaps in their implementation, particularly in limited-resource settings. ${ }^{68}$ Two large multilevel studies that combined phone or letter-based interventions with task-shifting to nurses or health workers were not successful in achieving a relevant improvement in adherence and BP control (Fairall et al, Goudge et al). ${ }^{32} 34$ On the other hand, no harm was observed after the expansion of the nurses' roles (Fairall et al). ${ }^{32}$ Thus, the intervention might be a practical and acceptable tool to expand the scope of non-physician clinicians into primary care of patients with common NCDs. There is a generally good access to essential medications in four countries where the included studies have been conducted (South Africa, Egypt, Kenya and Ghana). The access is not as widespread in Cameroon and Nigeria. ${ }^{77}$ Nevertheless, one study conducted in rural parts of South Africa between 2014 and 2015 (Goudge $e t a l)^{34}$ reported insufficient or unavailable equipment and medication shortage. Moreover, increasing numbers of patients with NCD require an adequate number of nursing personnel as well as healthcare facilities. Similar factors contributed to the poor results of the implementation of national guidelines in resource-scarce primary healthcare settings in South Africa ${ }^{62}$ which did not show improved outcomes in patients with hypertension and diabetes. In studies with follow-up-periods of less than 1 year, the time frame might have been too short to reach a clinically relevant BP control through improved knowledge and awareness, since lifestyle changes are oftentimes challenging and should be applied over a long time. ${ }^{24} 6166$ Generally, the results of the systematic review are consistent with existing evidence on the importance of long-acting patient-centred interventions. Unfortunately, these interventions do not reach all patients and often, a full benefit of medical treatment on clinically important outcomes cannot be achieved. ${ }^{78}$

Most studies in this review included participants in secondary prevention with mild to moderate hypertension. In contrast, observational studies and conclusions from a systematic review on pharmacological treatment generally concerned participants with higher grades of hypertension. ${ }^{579}$ Interventions for patients with severe or uncontrolled hypertension and potentially targetorgan damage are under-represented. Interventions for high-risk patients are especially necessary due to the high frequency of late first diagnosis ${ }^{7}$ and high prevalence of severe forms of hypertension at an early age in African patients. ${ }^{6}$ A multicentre study on patients with uncontrolled hypertension in clinics in Nigeria, Kenya 
Table 3 Risk of bias assessment

\begin{tabular}{|c|c|c|c|c|c|c|c|}
\hline \multirow[b]{2}{*}{ Study } & \multirow[b]{2}{*}{$\begin{array}{l}\text { Sequence } \\
\text { generation }\end{array}$} & \multirow[b]{2}{*}{$\begin{array}{l}\text { Allocation } \\
\text { concealment }\end{array}$} & \multicolumn{2}{|l|}{ Blinding of } & \multirow[b]{2}{*}{$\begin{array}{l}\text { Incomplete } \\
\text { outcome data }\end{array}$} & \multirow[b]{2}{*}{$\begin{array}{l}\text { Selective } \\
\text { reporting }\end{array}$} & \multirow[b]{2}{*}{$\begin{array}{l}\text { Other } \\
\text { sources }\end{array}$} \\
\hline & & & $\begin{array}{l}\text { Personnel/ } \\
\text { participants }\end{array}$ & $\begin{array}{l}\text { Outcome } \\
\text { assessors }\end{array}$ & & & \\
\hline \multicolumn{8}{|c|}{ Educational strategies } \\
\hline $\begin{array}{l}\text { Adeyemo et } \\
a l^{24}\end{array}$ & :) & (-) & (2) & (-) & (2) & ;) & (2) \\
\hline $\begin{array}{l}\text { Ayodapo and } \\
\text { Olukokun } 27\end{array}$ & $\odot$ & (i) & (2) & (2) & (i) & 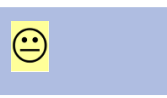 & 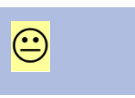 \\
\hline Bobrow et a ${ }^{28}$ & (i) & (i) & (2) & 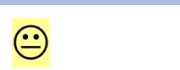 & ;:) & (:) & (i) \\
\hline $\begin{array}{l}\text { Bolarinwa et } \\
\text { al }{ }^{29}\end{array}$ & (i) & (i) & (2) & (2) & (2) & (2) & (2) \\
\hline Fairall et $a^{32}$ & (i) & (i) & (2) & $\odot$ & (:) & (;) & (i) \\
\hline Goudge et $\left.a\right|^{34}$ & (i) & (i) & (2) & (2) & (2) & (i) & (i) \\
\hline Gyamfi et al ${ }^{35}$ & (i) & (i) & (2) & $\ominus$ & (2) & (:) & (i) \\
\hline $\begin{array}{l}\text { Labhardt et } \\
a l^{36}\end{array}$ & (;) & (i) & (2) & (2) & (2) & (2) & (i) \\
\hline Mendis et $a l^{52}$ & 웅 & (2) & (2) & (2) & (2) & 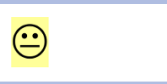 & (i) \\
\hline Owolabi et $\left.a\right|^{56}$ & (i) & $\odot$ & (2) & (i) & (i) & (2) & (i) \\
\hline Sarfo et $\left.a\right|^{58}$ & (i) & (i) & (:) & (i) & (i) & (i) & (i) \\
\hline $\begin{array}{l}\text { Saunders et } \\
\text { a/ }{ }^{60}\end{array}$ & () & (:) & (2) & (2) & (i) & ; & (i) \\
\hline Stewart et a/ ${ }^{61}$ & $\odot$ & 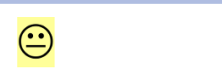 & (:) & (2) & (2) & $\odot$ & (i) \\
\hline Steyn et $a /^{62}$ & (i) & (i) & (2) & (2) & (i) & (i) & (i) \\
\hline $\begin{array}{l}\text { Vedanthan et } \\
a l^{64}\end{array}$ & 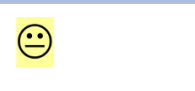 & (i) & (2) & (2) & ;:) & (i) & (2) \\
\hline Wahab et $a l^{66}$ & (i) & (i) & (2) & (:) & (i) & ; & (2) \\
\hline \multicolumn{8}{|c|}{ Standardised treatment } \\
\hline $\begin{array}{l}\text { Akintunde et } \\
a l^{25}\end{array}$ & (:) & $\odot$ & (: & $\odot$ & (2) & (i) & (2) \\
\hline $\begin{array}{l}\text { Okeahialam et } \\
\text { a }{ }^{55}\end{array}$ & (i) & (i) & (2) & $\odot$ & ;: & $\odot$ & (2) \\
\hline \multicolumn{8}{|c|}{ Physical activity } \\
\hline Aweto et $a^{26}$ & $\odot$ & ; & (2): & (2) & (2) & 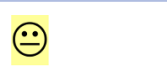 & (2): \\
\hline Lamina $^{37}$ & (2) & ; & (:) & (i) & (2) & (:) & (i) \\
\hline Maruf et $a 5^{51}$ & (i) & (i) & 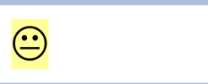 & (i) & (i) & (2) & (2) \\
\hline Khalid et $a f^{63}$ & (i) & (i) & (2) & (2) & (2) & $\Theta$ & (2) \\
\hline \multicolumn{8}{|c|}{ Modified nutrition } \\
\hline Charlton et $a l^{31}$ & 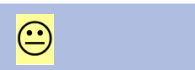 & ; & (i) & (i) & (i) & $\odot$ & (i) \\
\hline
\end{tabular}

(i): low; ${ }^{-} ;$: unclear; $;$: high risk of bias. 


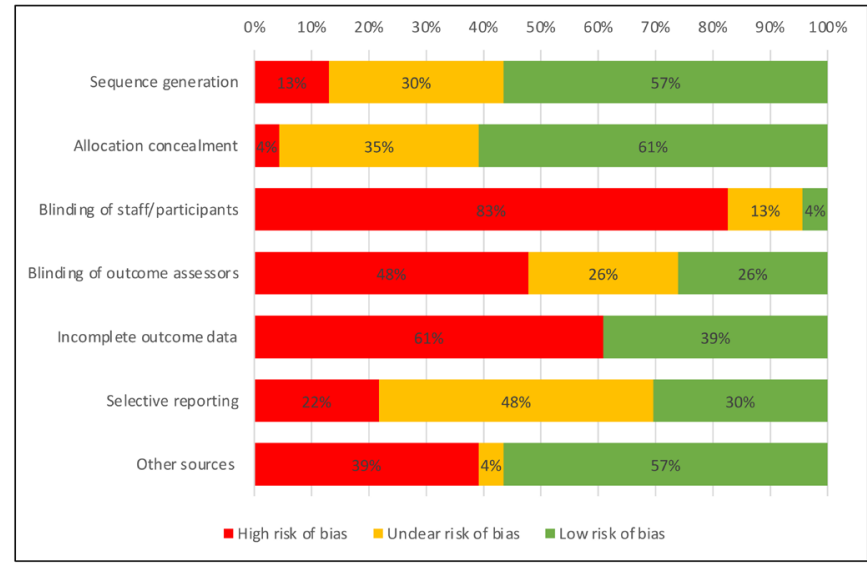

Figure 5 Summary of risk of bias.

and South Africa stated the efficacy of an individualised therapy based on phenotyping with plasma renin and aldosterone to improve BP control (Akintunde $e t a l$ ). ${ }^{25}$ The researchers suggest testing this approach in African Americans and patients of any race with therapy-resistant hypertension. Three studies ${ }^{56566}$ investigated the implementation of multilevel approaches including educational, telephone-based, nurse-led, self-management supporting interventions, as well as BP monitoring for stroke survivors. These studies were not successful in sufficiently improving BP control, possibly due to short follow-up periods.

Regarding the different grades of hypertension, low-risk patients with grade 1 hypertension benefit from lifestyle modifications including regular physical activity, sodium restriction, weight reduction, smoking cessation, moderation of alcohol consumption and other dietary changes. These are recommended as initial strategies to reduce BP levels in order to prevent or delay the use of pharmacotherapy. ${ }^{14}{ }^{15}$ Nevertheless, even for patients with higher grades of hypertension, lifestyle modifications remain important in addition to pharmacotherapy. ${ }^{14} 156980$ The clinically accepted relevant BP-lowering effect of mediumintensity to high-intensity physical activity as a single or additive treatment for hypertension ${ }^{81}$ was demonstrated in four of the included studies. ${ }^{26} 375163$ Only one study from South Africa investigated the effect of a modified nutrition strategy (reduction of salt intake) and stated a clinically relevant effect on SBP (Charlton et al). ${ }^{31}$ To the authors' knowledge, no randomised study investigated the efficacy of other recommended lifestyle interventions, like smoking cessation or weight reduction, in patients with hypertension in an African country.

\section{Strengths and limitations of this review}

We were able to generate evidence on a wide range of different non-pharmacological interventions, adding a comprehensive overview to the literature that can support physicians and healthcare policymakers in the African setting.

A main limitation occurs through deviations from the protocol. We planned a comprehensive summary of all
RCTs to prevent, diagnose and treat patients with CVDs in African countries. Due to a high number of eligible studies in the first systematic search, we decided to focus on published studies on hypertension. We therefore had to change the preplanned outcomes and instead focus on $\mathrm{BP}$ and additionally describe results on medication adherence and lifestyle changes. The preplanned outcomes mortality, New York Heart Association (NYHA) classification and hospital admission were dropped. Due to the recently published systematic review by Seeley $e t a l,{ }^{17}$ this publication describes non-pharmacological strategies. The complete results, including pharmacological interventions, were summarised in a doctoral thesis paper. ${ }^{82}$

Nevertheless, this review was limited to studies with the highest level of evidence to investigate the benefits and harms of non-pharmacological interventions for hypertension. The randomised allocation ensures the comparability of participants across intervention groups. However, the unfeasibility of double blinding might restrict the internal validity of results.

The external validity might be limited by our restriction to studies published in the English language and the disproportionally high number of studies conducted in urban areas in some Western and Southern African countries. According to the UN, there are currently 54 African countries. RCTs have been conducted in only six of those countries. Inhabitants of these countries (approximately 480 million) represent only a fraction of the African population of about 1.34 billion. ${ }^{83}$ Especially Central and Northern Africa were under-represented. There are high levels of diversity within and between African populations. Subpopulations with genetic variants are living in geographically distant areas with specific local lifestyle or environmental conditions, which may be associated with a susceptibility to specific NCDs. ${ }^{84}$ Therefore, it is uncertain whether our results can be extrapolated to patients living in other areas than those studied. A significant amount of the African population lives in rural areas while the majority of studies were conducted in urban settings. However, it is crucial to make health service available as close as possible to the population in order to achieve the most comprehensive care. Thus, research on nonpharmacological interventions such as educational strategies to improve adherence and lifestyle modification should be expanded across all parts of Africa. Research must be conducted especially in rural areas to ensure a higher generalisability, quality of services and resulting improvement of the African people's health.

\section{CONCLUSION}

This systematic review shows that even though hypertension is a critical health problem, there are still few randomised studies on non-pharmacological treatment of hypertension conducted on the African continent. Available studies do not represent all Africans since they were conducted in only six countries, many in urban settings only. It is advisable to plan and implement studies on 
patients with hypertension and healthcare professionals in rural areas as well as Northern and Central African countries.

An improvement in the prognosis of patients with high BP in Africa requires the implementation of practical and effective solutions to diagnose, treat and control hypertension in specific settings. ${ }^{9}$ The identified studies describe diverse approaches tested in African countries that may be used to generate local African evidencebased guidelines on hypertension treatment. Especially trialled physical activity interventions and individualised treatment strategies show clinically relevant BP changes. Educational strategies for patients and medical personnel show mixed results and offer a comprehensive insight into trialled approaches as well as a basis for future research opportunities. This review summarises miscellaneous low-cost interventions including task-shifting, education individualised treatment and lifestyle modifications to improve BP control.

\section{Author affiliations \\ ${ }^{1}$ Institute of General Practice and Family Medicine, Center of Health Sciences, Martin-Luther-Universität Halle-Wittenberg Medizinische Fakultät, Halle, Germany ${ }^{2}$ School of Public Health, Addis Ababa University, Addis Ababa, Ethiopia ${ }^{3}$ Institute for Medical Epidemiology, Biostatistics and Informatics, Center of Health Sciences, Martin-Luther-Universität Halle-Wittenberg Medizinische Fakultät, Halle, Germany \\ ${ }^{4}$ Physiotherapy Department, Regional Hospital Bamenda, Bamenda, Cameroon ${ }^{5}$ Research Organization for Health Education and Rehabilitation-Cameroon(ROHER- CAM), St. Louis University Bamenda, Bamenda, Cameroon \\ ${ }^{6}$ African Regional Community, Guidelines International Network (G-I-N), Bamenda, Cameroon \\ ${ }^{7}$ Department of Primary Care, Universität Leipzig Medizinische Fakultät, Leipzig, Germany}

Contributors MC was involved in all steps to plan this systematic review including the protocol; wrote the draft of this manuscript; screened titles, abstracts, and full texts; and did data extraction and quality assessment. ESK wrote the draft of this manuscript; screened titles, abstracts and full texts; did data extraction and quality assessment of the last update; and submitted the manuscript. TD was involved in all steps to plan this systematic review including the protocol; provided expertise and discussed the results in the African context; and commented on the manuscript. TF provided expertise on primary care aspects of hypertension treatment, discussed the results and commented on the manuscript. SG provided expertise on CVD epidemiology and public health, discussed the results in the African context and commented on the manuscript. EJK was involved in all steps to plan this systematic review including the protocol; provided expertise on the needs of evidence in the African context; and commented on the manuscript. EN provided expertise on public health and African guideline work, discussed the results in the African context, commented on the manuscript, provided expertise and discussed the reviewer comments and supported the draft of the revised manuscript. SU is responsible for the overall content as the guarantor and was involved in all steps to plan this systematic review including the protocol; wrote the draft of this manuscript; made systematic search; screened titles, abstracts and full texts; did data extraction and quality assessment; and submitted the manuscript.

Funding The authors have not declared a specific grant for this research from any funding agency in the public, commercial or not-for-profit sectors.

Competing interests None declared.

Patient consent for publication Not required.

Ethics approval No ethics approval and consent to participate was necessary.

Provenance and peer review Not commissioned; externally peer reviewed.

Data availability statement All data relevant to the study are included in the article or uploaded as supplemental information.
Supplemental material This content has been supplied by the author(s). It has not been vetted by BMJ Publishing Group Limited (BMJ) and may not have been peer-reviewed. Any opinions or recommendations discussed are solely those of the author(s) and are not endorsed by BMJ. BMJ disclaims all liability and responsibility arising from any reliance placed on the content. Where the content includes any translated material, BMJ does not warrant the accuracy and reliability of the translations (including but not limited to local regulations, clinical guidelines, terminology, drug names and drug dosages), and is not responsible for any error and/or omissions arising from translation and adaptation or otherwise.

Open access This is an open access article distributed in accordance with the Creative Commons Attribution Non Commercial (CC BY-NC 4.0) license, which permits others to distribute, remix, adapt, build upon this work non-commercially, and license their derivative works on different terms, provided the original work is properly cited, appropriate credit is given, any changes made indicated, and the use is non-commercial. See: http://creativecommons.org/licenses/by-nc/4.0/.

ORCID iDs

Eric Sven Kroeber http://orcid.org/0000-0002-7201-6023

Eva Johanna Kantelhardt http://orcid.org/0000-0001-7935-719X

Susanne Unverzagt http://orcid.org/0000-0002-0108-0415

\section{REFERENCES}

1 Global Burden of Metabolic Risk Factors for Chronic Diseases Collaboration. Cardiovascular disease, chronic kidney disease, and diabetes mortality burden of cardiometabolic risk factors from 1980 to 2010: a comparative risk assessment. Lancet Diabetes Endocrinol 2014;2:634-47.

2 NCD Risk Factor Collaboration (NCD-RisC). Worldwide trends in blood pressure from 1975 to 2015: a pooled analysis of 1479 population-based measurement studies with $19 \cdot 1$ million participants. Lancet 2017;389:37-55.

3 Kaze AD, Schutte AE, Erqou S, et al. Prevalence of hypertension in older people in Africa: a systematic review and meta-analysis. $J$ Hypertens 2017;35:1345-52.

4 Bosu WK, Reilly ST, Aheto JMK, et al. Hypertension in older adults in Africa: a systematic review and meta-analysis. PLoS One 2019;14:e0214934.

5 Brewster LM, Seedat YK. Why do hypertensive patients of African ancestry respond better to calcium blockers and diuretics than to ACE inhibitors and $\beta$-adrenergic blockers? A systematic review. BMC Med 2013;11:141.

6 Brewster LM, van Montfrans GA, Oehlers GP, et al. Systematic review: antihypertensive drug therapy in patients of African and South Asian ethnicity. Intern Emerg Med 2016;11:355-74.

7 Oladapo OO, Salako L, Sadiq L, et al. Target-organ damage and cardiovascular complications in hypertensive Nigerian Yoruba adults: a cross-sectional study. Cardiovasc J Afr 2012;23:379-84.

8 Nelissen HE, Hendriks ME, Wit FWNM, et al. Target organ damage among hypertensive adults in rural Nigeria: a cross-sectional study. $J$ Hypertens 2014;32:487-94.

9 Dzudie A, Rayner B, Ojji D, et al. Roadmap to achieve 25\% hypertension control in Africa by 2025. Cardiovasc J Afr 2017;28:262-72.

10 United Nations. Sustainable development goals. Goal 3: ensure healthy living and promote well-being for all at all ages, 2019. Available: https://www.un.org/sustainabledevelopment/health/

11 Gómez-Olivé FX, Ali SA, Made F, et al. Regional and sex differences in the prevalence and awareness of hypertension: an H3Africa AWI-Gen study across 6 sites in sub-Saharan Africa. Glob Heart 2017;12:81-90.

12 Lloyd-Sherlock P, Beard J, Minicuci N, et al. Hypertension among older adults in low- and middle-income countries: prevalence, awareness and control. Int J Epidemiol 2014;43:116-28.

13 Guwatudde D, Nankya-Mutyoba J, Kalyesubula R, et al. The burden of hypertension in sub-Saharan Africa: a four-country cross sectional study. BMC Public Health 2015;15:1211.

14 Whelton PK, Carey RM, Aronow WS, et al. 2017 ACC/AHA/AAPA/ ABC/ACPM/AGS/APhA/ASH/ASPC/NMA/PCNA guideline for the prevention, detection, evaluation, and management of high blood pressure in adults: Executive summary: a report of the American College of Cardiology/American heart association Task force on clinical practice guidelines. Hypertension 2018;71:1269-324.

15 Williams B, Mancia G, Spiering W, et al. 2018 ESC/ESH guidelines for the management of arterial hypertension. Eur Heart $J$ 2018;39:3021-104. 
16 Fredericksen RJ, Gibbons L, Brown S, et al. Medication understanding among patients living with multiple chronic conditions: implications for patient-reported measures of adherence. Res Social Adm Pharm 2018:14:540-4.

17 Seeley A, Prynn J, Perera R, et al. Pharmacotherapy for hypertension in sub-Saharan Africa: a systematic review and network metaanalysis. BMC Med 2020;18:1-11.

18 Mahmood S, Shah KU, Khan TM, et al. Non-pharmacological management of hypertension: in the light of current research. Ir J Med Sci 2019;188:437-52.

19 Moher D, Liberati A, Tetzlaff J, et al. Preferred reporting items for systematic reviews and meta-analyses: the PRISMA statement. PLoS Med 2009;6:e1000097.

20 Boutron I, Altman DG, Moher D, et al. Consort statement for randomized trials of nonpharmacologic treatments: a 2017 update and a consort extension for nonpharmacologic trial Abstracts. Ann Intern Med 2017;167:40-7.

21 Team TE. EndNote. EndNote X9 ed. Philadelphia, PA: Clarivate, 2013.

22 Higgins JPT, Altman DG, Gøtzsche PC, et al. The Cochrane collaboration's tool for assessing risk of bias in randomised trials. BMJ 2011;343:d5928.

23 Collaboration Copenhagen TC. Review Manager (RevMan) [Computer program]. Version 5.3, 2014.

24 Adeyemo A, Tayo BO, Luke A, et al. The Nigerian antihypertensive adherence trial: a community-based randomized trial. $J$ Hypertens 2013;31:201-7.

25 Akintunde A, Nondi J, Gogo K, et al. Physiological phenotyping for personalized therapy of uncontrolled hypertension in Africa. Am J Hypertens 2017;30:923-30.

26 Aweto HA, Owoeye OBA, Akinbo SRA, et al. Effects of dance movement therapy on selected cardiovascular parameters and estimated maximum oxygen consumption in hypertensive patients. Nig Q J Hosp Med 2012;22:125-9.

27 Ayodapo AO, Olukokun TAV. Lifestyle counselling and behavioural change: role among adult hypertensives in a rural tertiary institution. South African Family Practice 2019;61:91-6.

28 Bobrow K, Farmer AJ, Springer D, et al. Mobile Phone Text Messages to Support Treatment Adherence in Adults With High Blood Pressure (SMS-Text Adherence Support [StAR]): A SingleBlind, Randomized Trial. Circulation 2016;133:592-600.

29 Bolarinwa OA, Juni $\mathrm{MH}$, Nor Afiah $\mathrm{MZ}$, et al. Mid-term impact of home-based follow-up care on health-related quality of life of hypertensive patients at a teaching hospital in Ilorin, Nigeria. Niger $J$ Clin Pract 2019;22:69-78.

30 Cappuccio FP, Kerry SM, Micah FB, et al. A community programme to reduce salt intake and blood pressure in Ghana [ISRCTN88789643]. BMC Public Health 2006;6:13.

31 Charlton KE, Steyn K, Levitt NS, et al. A food-based dietary strategy lowers blood pressure in a low socio-economic setting: a randomised study in South Africa. Public Health Nutr 2008;11:1397-406. [Erratum appears in Public Health Nutr 2009;12:284]

32 Fairall LR, Folb N, Timmerman V, et al. Educational outreach with an integrated clinical tool for nurse-led non-communicable chronic disease management in primary care in South Africa: a pragmatic cluster randomised controlled trial. PLoS Med 2016;13:e1002178.

33 Folb N, Timmerman V, Levitt NS, et al. Multimorbidity, control and treatment of noncommunicable diseases among primary healthcare attenders in the Western Cape, South Africa. S Afr Med $J$ 2015;105:642-7.

34 Goudge J, Chirwa T, Eldridge S, et al. Can lay health workers support the management of hypertension? Findings of a cluster randomised trial in South Africa. BMJ Glob Health 2018;3:e000577.

35 Gyamfi J, Plange-Rhule J, Iwelunmor J, et al. Training nurses in task-shifting strategies for the management and control of hypertension in Ghana: a mixed-methods study. BMC Health Serv Res 2017:17:104.

36 Labhardt ND, Balo J-R, Ndam M, et al. Improved retention rates with low-cost interventions in hypertension and diabetes management in a rural African environment of nurse-led care: a cluster-randomised trial. Trop Med Int Health 2011;16:1276-84.

37 Lamina S. Effects of continuous and interval training programs in the management of hypertension: a randomized controlled trial. J Clin Hypertens 2010;12:841-9.

38 Lamina S. Comparative effect of interval and continuous training programs on serum uric acid in management of hypertension: a randomized controlled trial. J Strength Cond Res 2011;25:719-26.

39 Lamina S, Okoye CG. Effect of low intensity continuous training programme on serum uric acid in the non pharmacological management of hypertension: a randomized controlled trial. Niger J Med 2010;19:77-86.
40 Lamina S, Okoye CG. Uricaemia as a cardiovascular events risk factor in hypertension: the role of interval training programme in its downregulation. J Assoc Physicians India 2011;59:23-8.

41 Lamina S, Okoye CG. Effect of interval training program on white blood cell count in the management of hypertension: a randomized controlled study. Niger Med J 2011;52:271-7.

42 Lamina S, Okoye CG, Dagogo TT. Managing erectile dysfunction in hypertension: the effects of a continuous training programme on biomarker of inflammation. BJU Int 2009;103:1218--21.

43 Lamina S, Okoye CG, Dagogo TT. Therapeutic effect of an interval exercise training program in the management of erectile dysfunction in hypertensive patients. J Clin Hypertens 2009;11:125-9.

44 Lamina S, Okoye CG, Hanif SM. Randomised controlled trial: effects of aerobic exercise training programme on indices of adiposity and metabolic markers in hypertension. J Pak Med Assoc 2013;63:680-7.

45 Lamina S, Okoye CG, Hanif SM. Effects of interval exercise training programme on the indices of adiposity and biomarker of inflammation in hypertension: a randomised controlled trial. Niger Postgrad Med J 2014;21:136-43.

46 Lamina S, Okoye G. Effects of aerobic exercise training on psychosocial status and serum uric acid in men with essential hypertension: a randomized controlled trial. Ann Med Health Sci Res 2012;2:161-8.

47 Lamina S, Okoye GC. Therapeutic effect of a moderate intensity interval training program on the lipid profile in men with hypertension: a randomized controlled trial. Niger J Clin Pract 2012;15:42-7.

48 Lamina S, Okoye GC. Effect of interval exercise training programme on C-reactive protein in the non-pharmacological management of hypertension: a randomized controlled trial. Afr J Med Med Sci 2012;41:379-86.

49 Leon N, Surender R, Bobrow K, et al. Improving treatment adherence for blood pressure lowering via mobile phone SMS-messages in South Africa: a qualitative evaluation of the SMS-text adherence support (StAR) trial. BMC Fam Pract 2015;16:80

50 Maruf FA, Akinpelu AO, Salako BL. Self-reported quality of life before and after aerobic exercise training in individuals with hypertension: a randomised-controlled trial. Appl Psychol Health Well Being 2013;5:209-24.

51 Maruf FA, Akinpelu AO, Salako BL, et al. Effects of aerobic dance training on blood pressure in individuals with uncontrolled hypertension on two antihypertensive drugs: a randomized clinical trial. J Am Soc Hypertens 2016;10:336-45.

52 Mendis S, Johnston SC, Fan W, et al. Cardiovascular risk management and its impact on hypertension control in primary care in low-resource settings: a cluster-randomized trial. Bull World Health Organ 2010;88:412-9.

53 Ogedegbe G, Plange-Rhule J, Gyamfi J, et al. Health insurance coverage with or without a nurse-led task shifting strategy for hypertension control: a pragmatic cluster randomized trial in Ghana. PLoS Med 2018;15:e1002561.

54 Ogedegbe G, Plange-Rhule J, Gyamfi J, et al. A cluster-randomized trial of task shifting and blood pressure control in Ghana: study protocol. Implement Sci 2014;9:73.

55 Okeahialam B, Ohihoin E, Ajuluchukwu J. Chronotherapy in Nigerian hypertensives. Ther Adv Cardiovasc Dis 2011;5:113-8.

56 Owolabi MO, Gebregziabher M, Akinyemi RO, et al. Randomized trial of an intervention to improve blood pressure control in stroke survivors. Circ Cardiovasc Qual Outcomes 2019;12:e005904.

57 Sarfo FS, Ovbiagele B. Stroke minimization through additive antiatherosclerotic agents in routine treatment (SMAART): a pilot trial concept for improving stroke outcomes in sub-Saharan Africa. $J$ Neurol Sci 2017;377:167-73.

58 Sarfo FS, Treiber F, Gebregziabher M, et al. Phone-based intervention for blood pressure control among Ghanaian stroke survivors: a pilot randomized controlled trial. Int J Stroke 2019;14:630-8.

59 Sarfo FS, Treiber F, Jenkins C, et al. Phone-based intervention under nurse guidance after stroke (PINGS): study protocol for a randomized controlled trial. Trials 2016;17:436.

60 Saunders LD, Irwig LM, Gear JS, et al. A randomized controlled trial of compliance improving strategies in Soweto hypertensives. Med Care 1991;29:669-78.

61 Stewart A, Noakes T, Eales C, et al. Adherence to cardiovascular risk factor modification in patients with hypertension. Cardiovasc J S Afr 2005;16:102-7.

62 Steyn K, Lombard C, Gwebushe N, et al. Implementation of national guidelines, incorporated within structured diabetes and hypertension records at primary level care in Cape Town, South Africa: a randomised controlled trial. Glob Health Action 2013:6:20796.

63 Khalid T, Nesreen E, Ramadhan O. Effects of exercise training on postmenopausal hypertension: implications on nitric oxide levels. Med J Malaysia 2013;68:459-64. 
64 Vedanthan R, Kamano JH, DeLong AK, et al. Community Health Workers Improve Linkage to Hypertension Care in Western Kenya. $J$ Am Coll Cardiol 2019;74:1897-906.

65 Vedanthan R, Kamano JH, Naanyu V, et al. Optimizing linkage and retention to hypertension care in rural Kenya (LARK hypertension study): study protocol for a randomized controlled trial. Trials 2014:15:143

66 Wahab KW, Owolabi M, Akinyemi R, et al. Short-term pilot feasibility study of a nurse-led intervention to improve blood pressure control after stroke in Nigeria. J Neurol Sci 2017;377:116-20.

67 Jagannathan R, Patel SA, Ali MK, et al. Global updates on cardiovascular disease mortality trends and attribution of traditional risk factors. Curr Diab Rep 2019;19:44.

68 Jeemon P, Gupta R, Onen C. In: Prabhakaran D, Anand S, Gaziano TA, eds. Management of hypertension and dyslipidemia for primary prevention of cardiovascular diseases. World Bank Publications, 2017: 444.

69 Noone C, Leahy J, Morrissey EC, et al. Comparative efficacy of exercise and anti-hypertensive pharmacological interventions in reducing blood pressure in people with hypertension: a network meta-analysis. Eur J Prev Cardiol 2020;27:247-55.

70 Burnier M. Drug adherence in hypertension. Pharmacol Res 2017:125:142-9.

71 GBD 2017 Causes of Death Collaborators. Global, regional, and national age-sex-specific mortality for 282 causes of death in 195 countries and territories, 1980-2017: a systematic analysis for the global burden of disease study 2017. Lancet 2018;392:1736-88.

72 Nielsen J Ø, Shrestha AD, Neupane D, et al. Non-adherence to anti-hypertensive medication in low- and middle-income countries: a systematic review and meta-analysis of 92443 subjects. J Hum Hypertens 2017;31:14-21.

73 Ajiboye RO, Okafor NA, Abiodun IO. Knowledge and practice of lifestyle modification among hypertensive patients in a general Hospital Lagos. Indian J Commun Health 2015;27:143-9.
74 Tedla YG, Bautista LE. Drug side effect symptoms and adherence to antihypertensive medication. Am J Hypertens 2016;29:772-9.

75 Goel MK. Non-adherence to anti-hypertensive treatment. Indian J Commun Health 2020;32:126-9.

$76 \mathrm{Xu} \mathrm{T,} \mathrm{Yu} \mathrm{X,} \mathrm{Ou} \mathrm{S,} \mathrm{et} \mathrm{al.} \mathrm{Adherence} \mathrm{to} \mathrm{antihypertensive} \mathrm{medications}$ and stroke risk: a dose-response meta-analysis. J Am Heart Assoc 2017;6. doi:10.1161/JAHA.117.006371. [Epub ahead of print: $25 \mathrm{Jul}$ 2017].

77 WHO. Noncommunicable diseases country profiles. Geneva: World Health Organization, 2018

78 Nieuwlaat R, Wilczynski N, Navarro T, et al. Interventions for enhancing medication adherence. Cochrane Database Syst Rev 2014:11:CD000011.

79 Ayodele OE, Alebiosu CO, Akinwusi PO, et al. Target organ damage and associated clinical conditions in newly diagnosed hypertensives attending a tertiary health facility. Niger J Clin Pract 2007;10:319-25.

80 Hypertension guideline working group, Seedat YK, Rayner BL, et al. South African hypertension practice guideline 2014. Cardiovasc J Afr 2014;25:288-94.

81 Börjesson M, Onerup A, Lundqvist S, et al. Physical activity and exercise lower blood pressure in individuals with hypertension: narrative review of 27 RCTs. Br J Sports Med 2016;50:356-61.

82 Cernota MD. Randomized controlled trials on prevention, diagnosis and treatment of hypertension in Africa, a systematic review 2020.

83 United Nations. World population prospects, 2019. Department of economic and social Affairs, population division. Available: https:// population.un.org/wpp/Download/Standard/Population/ [Accessed 21 Sep 2020].

84 Gomez F, Hirbo J, Tishkoff SA. Genetic variation and adaptation in Africa: implications for human evolution and disease. Cold Spring Harb Perspect Biol 2014;6:a008524. 